\title{
ANÁLISE QUANTITATIVA DOS MINERAIS PESADOS NA PLATAFORMA CONTINENTAL INTERNA ADJACENTE AO LITORAL CENTRO-NORTE DE SANTA CATARINA
}

\author{
SOUZA, D.R. \& ABREU, J.G.N. \\ Universidade do Vale do Itajaí - UNIVALI; Centro de Ciências Tecnológicas da Terra e do Mar - \\ CTTMar; Laboratório de Oceanografia Geológica - LOG \\ CTTMar/UNIVALI, CX.P. 360, Itajaí, SC, Brasil. oceanodrs@yahoo.com.br; gabreu@univali.br
}

\begin{abstract}
Souza, D.R. \& Abreu, J.G.N. 2005. Quantitative analysis of heavy mineral in the adjacent continental shelf to the center-north coast of the Santa Catarina state. Braz. J. Aquat. Sci. Technol. 9(1):1-5. ISSN 1808-7035. Heavy minerals are detritics material originated from igneous, sedimentary and metamorfic rocks, having specific weight superior to the most common minerals, as quartz and feldspat. Its occurrence in coastal and marine continental deposits allows to infer in regard to the evolution of these environments, outstanding as an important tool for Sedimentology and Estratigrafy. Its provenience and distribution trend contribute for the sedimentologic and mineralogic characterization of the deposicional environment, detailing relative sedimentary aspects to each environment. In petroliferous exploration, they are used in the interpretation of the ambient processes and in the analysis of the sedimentary basins. When found in concentrations higher than $1 \%$ in relation to the studied fraction it can became economically viable for the exploration and then they are known as placers. Amongst placers of economic value outstand those of ilmenite, rutile, zircon, monazite and magnetite, concentrating in high-energy environments after the disaggregation of the rocks source. Exist in Santa Catarina continental shelf the need of more detailed studies about the mineral species, its concentrations and its distribution areas. Thus, this studied can give start to a series of researches referent to this mineral good and contributes to the production of important bibliographical references for the Southern-Brazilian Continental Edge.
\end{abstract}

Keywords: Heavy Mineral, Sedimentology, Continental Shelf.

\section{INTRODUÇÃO}

Mineral pesado é definido como um mineral detrítico originado de uma rocha ígnea, sedimentar ou metamórfica, após litificação, tendo peso específico maior que $2,85 \mathrm{~g} / \mathrm{cm}^{3}$ e comumente formando constituintes menores ou minerais acessórios das rochas (Bates \& Jackson, 1980). Segundo Suguio (1980), os minerais pesados têm um peso específico maior do que os minerais mais comuns das rochas sedimentares, como feldspato e quartzo, cujo peso específico é de $2,6 \mathrm{~g} / \mathrm{cm}^{3}$. A quantidade dos minerais pesados em um determinado local depende da sua abundância na área fonte e da intensidade do processo de transporte, que inclui a sua capacidade de resistência ao intemperismo, à abrasão e a sua segregação devido a diferenças na densidade e forma (Addad, 2001).

A importância atribuída aos minerais pesados provém da aplicabilidade de seu estudo e a interpretação dos resultados em vários aspectos relacionados à Sedimentologia, Estratigrafia e a Geologia Econômica.

Sua ocorrência em depósitos continentais costeiros e marinhos permite inferir a respeito da evolução destes ambientes, no qual destacam-se como ferramenta importante para a Sedimentologia e Estratigrafia (Palma, 1979).
As concentrações de minerais pesados são consideradas nos estudos de proveniência e dispersão dos sedimentos, pois os mesmos são característicos de determinados tipos de rochas fontes (Krumbein \& Pettijohn, 1938, Krumbein \& Sloss, 1956, FeoCodecido, 1956, Pettijohn, 1957), bem como a sua distribuição permite identificar direções preferenciais de transporte sedimentar (Tomazelli, 1978; Mezzadri \& Saccani, 1989; Calliari et al., 1990). Representam também importante ferramenta na reconstituição de ambientes antigos, e na exploração petrolífera são usados na análise das bacias sedimentares e como indicadores de processos ambientais (Addad, 2001).

Quando encontrados em concentrações maiores que $1 \%$ em relação à fração estudada, podem tornar-se viáveis economicamente para a exploração e são, então, depósitos conhecidos como pláceres (Palma, 1979). Dentre os pláceres de valor econômico destacam-se os de ilmenita, rutilo, zircão, monazita, magnetita, cassiterita, ouro e diamante, concentrandose em ambientes de alta energia, após a desagregação das rochas fonte. Associam-se a eles importantes concentrações de ferro, titânio, tório, zinco e muitos outros metais estratégicos que podem ser passíveis de explotação. 
Desde a costa do Pará até a do Rio Grande do Sul, encontram-se sítios com elevadas concentrações de minerais pesados em depósitos emersos, ocorrendo algumas explorações na Paraíba, Espírito Santo e Rio de Janeiro (Santana, 1997). No entanto, nos depósitos imersos, como a plataforma continental, existe uma carência de estudos mais detalhados sobre as espécies minerais, suas concentrações e áreas de distribuição (Abreu, 1998), principalmente ao longo do litoral do Estado de Santa Catarina. Neste sentido, o Projeto Reconhecimento Global da Margem Continental Brasileira - (REMAC) - (in Palma, 1979), que, além de realizar um amplo levantamento da forma e natureza de toda a margem continental brasileira, buscou a investigação e mapeamento das áreas com potencial econômico em matéria de petróleo e depósitos minerais.

Com o objetivo de suprir esta carência de dados, este trabalho visa identificar as espécies de minerais pesados, estimar sua abundância e mapear a sua distribuição, através da identificação e análises quali-quantitativas dos minerais pesados nas frações granulométricas de 1-2 phi, 2-3 phi e 3-4 phi.

O presente trabalho, portanto contribui para os estudos de caracterização sedimentológica da Plataforma Continental Interna de Santa Catarina, constituindo-se num trabalho pioneiro no reconhecimento dos depósitos de minerais pesados e na determinação da sua potencial explotação econômica.

\section{MATERIAL E MÉTODOS}

A área de estudo situa-se na Plataforma Continental Interna adjacente ao litoral Norte do Estado de Santa Catarina, que compreende a região localizada entre a foz dos rios Itapocu, ao norte ( $\left.26^{\circ} 30^{\prime} 00^{\prime \prime}\right)$ e do rio Tijucas ao sul ( $\left.27^{\circ} 20^{\prime} 00^{\prime \prime}\right)$. A isóbata de 50 metros caracteriza o limite leste da referida área (Fig. 1).

Primeiramente, foi efetuada a separação gravitativa de minerais leves e pesados por líquido denso (Bromofórmio), nas frações de tamanho de 1-2, 2-3 e 3-4 phi, presentes em 38 amostras coletadas na plataforma continental, entre 10 e $50 \mathrm{~m}$ de profundidade durante a operação Geocosta Sul 002 / SC em 1997. Posteriormente foram contados e identificados cerca de 300 grãos de minerais pesados e, em seguida, executada a plotagem dos dados para a confecção de mapas de concentração de minerais pesados.

\section{RESULTADO E DISCUSSÃO}

Assim como foi visto por Tomazelli (1978), em relação às classes granulométricas analisadas, pôde ser observado que a maior concentração de minerais pesados está associada à classe 3-4 phi, correspondente à parcela mais fina da fração areia, onde o diâmetro dos grãos varia entre 0,125 a 0,062 mm.

De acordo com os mapas de distribuição de minerais pesados, foi possível observar duas áreas de elevada concentração, situadas próximo à costa, ao norte da desembocadura do rio Itajaí-Açú e ao largo do rio Itapocu. Nestes locais os teores totais alcançaram até $1,57 \%$ de minerais pesados no sedimento analisado somando-se as três frações, ou seja, as frações de 1 a 4 phi, indicando uma contribuição sedimentológica atual destes rios para a plataforma continental interna. No nordeste da área de estudo e nas proximidades da llha da Galé (Fig.2) também ocorrem concentrações de minerais pesados porém com concentrações menos significativas. Especificamente, para a fração correspondente a 3-4 phi (areia muito fina), podem ser observados em determinados locais, concentrações de minerais pesados que alcançam até $6 \%$, principalmente próximo a desembocadura do rio Itapocu, no centro e bem ao sul da área de estudo (Fig. 3). Já para a classe 2-3 phi (areia fina), existem acumulações de minerais pesados de até $1,05 \%$, se concentrando principalmente próximas as desembocaduras dos rios Itapocu e ItajaíAçú, e a nordeste da área de estudo (Fig. 4). Na classe 1-2 phi (areia média), as concentrações de minerais pesados chegam até 1,4\% (Fig. 5), se concentrando quase que exclusivamente próxima a desembocadura do rio Itajaí-Açú.

As principais espécies mineralógicas encontradas estão descritas na figura 6 . Esporadicamente, também foi registrada a presença de leucoxênio, muscovita,

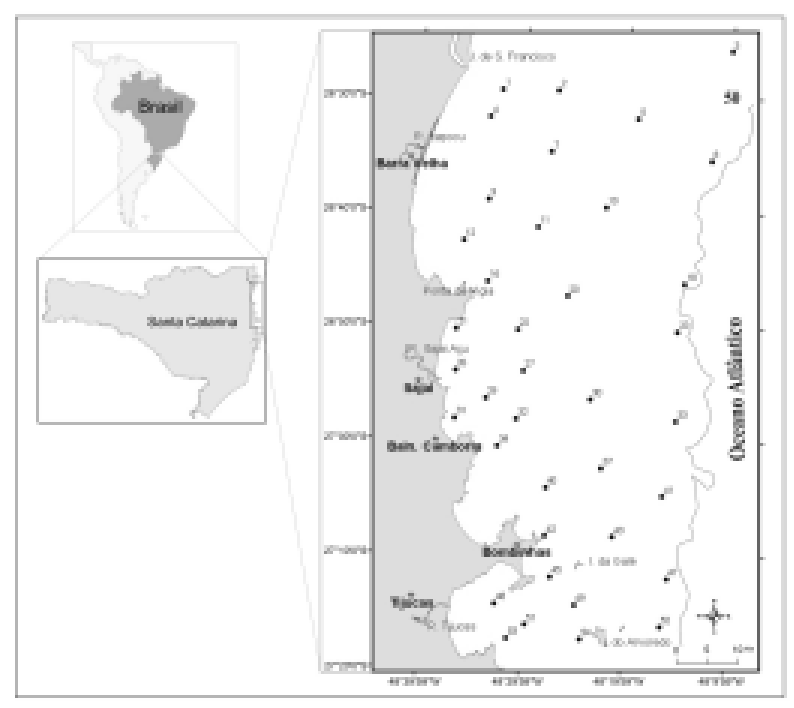

Figura 1: Localização da área de estudo. 
silimanita, olivina, esfeno, actinolita, apatita, espinélio, andalusita, limonita, pirita, biotita, cromita e alanita.

Os minerais menos maturos ou instáveis (augita, hornblenda e hiperstênio) segundo a classificação de Pettijohn (1957), se concentraram ao norte das desembocaduras dos rios Itajaí-Açu e Tijucas, de acordo com o mapa do Índice ZTR (Zircão, Turmalina, Rutilo). Já os minerais mais maturos ou estáveis (principalmente a turmalina) segundo esta mesma classificação, se apresentam à noroeste e mais ao centro da área de estudo e principalmente, ao sul, próximo a llha do Arvoredo.

\section{CONCLUSÕES}

Em relação às classes granulométricas analisadas, a maior concentração de minerais pesados está associada à classe 3-4 phi, que corresponde à parcela mais fina da fração areia.

Os resultados sugerem uma maior concentração de pesados nos locais adjacentes à costa, principalmente próximo às desembocaduras dos rios ItajaíAçú e Itapocu, indicando uma possível contribuição destes sistemas de drenagem para a plataforma continental. Este aumento da concentração nestas áreas

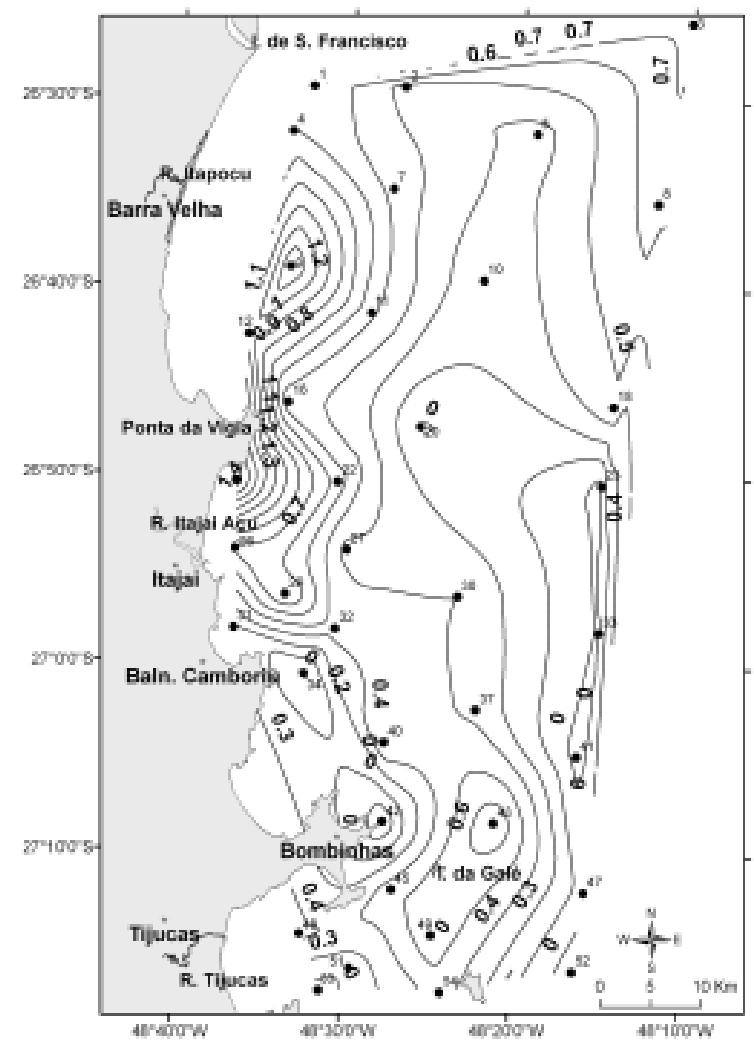

Figura 2: Mapa de concentração total de minerais pesados. leva-nos a crer que o aporte sedimentar dos rios tem efetiva contribuição para a sedimentologia da plataforma, já que os mesmos abrangem uma área de drenagem relativamente grande apresentando uma variada litologia.

As espécies minerais encontradas foram: ilmenita, epidoto, turmalina, augita, magnetita, diopsidio, zircão, hornblenda, cianita, estaurolita, hiperstênio, granada, rutilo, leucoxênio, muscovita, silimanita, olivina, esfeno, actinolita, apatita, espinélio, andalusita, limonita, pirita, biotita, cromita e alanita.

A maior concentração é dos minerais transparentes $(54,11 \%)$, sendo o mineral mais abundante a ilmenita com $31,79 \%$. Os minerais opacos aparecem com concentração de 43,2\%.

Sob o ponto de vista econômico, este estudo revelou a ocorrência de alguns minerais pesados em concentrações superiores a $1 \%$. Todavia para se considerar estes depósitos como pláceres são necessários estudos mais detalhados para melhor definir os processos de concentração. Entretanto, os resultados indicaram uma tendência de distribuição dos minerais instáveis, que estaria associada a fatores como a forma e a densidade destes grãos e, também devido à ação das correntes, que nesta área, teria direção S-N

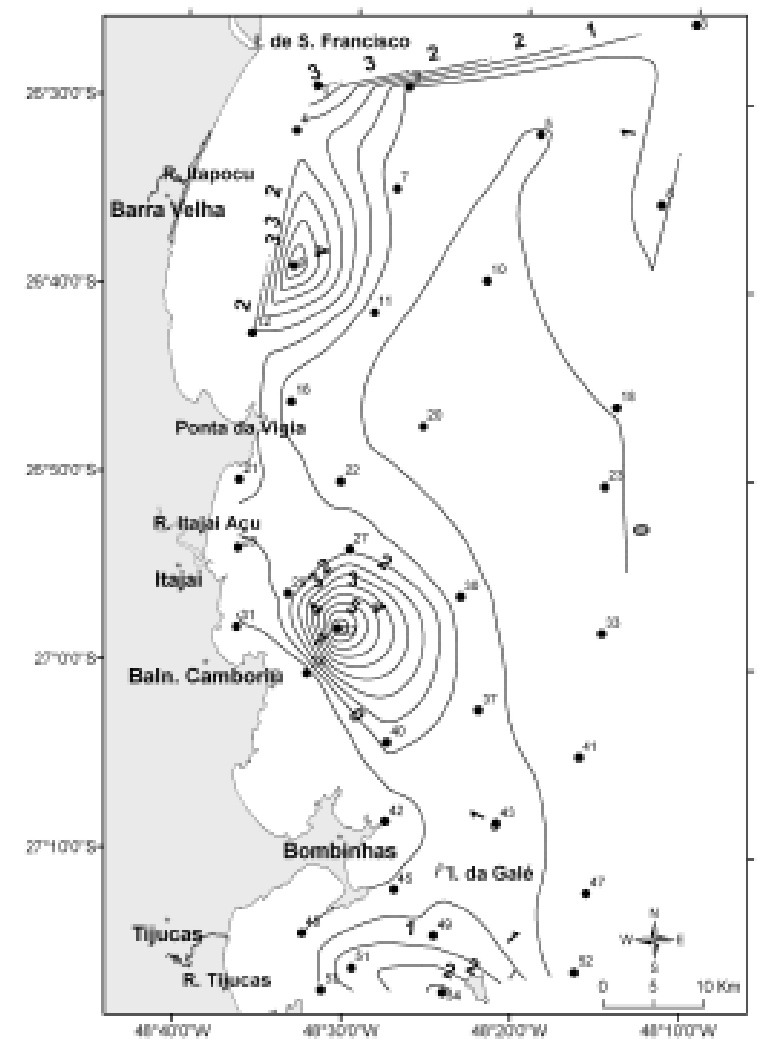

Figura 3: Mapa de concentração de minerais pesados na fração areia muito fina (3-4 phi). 


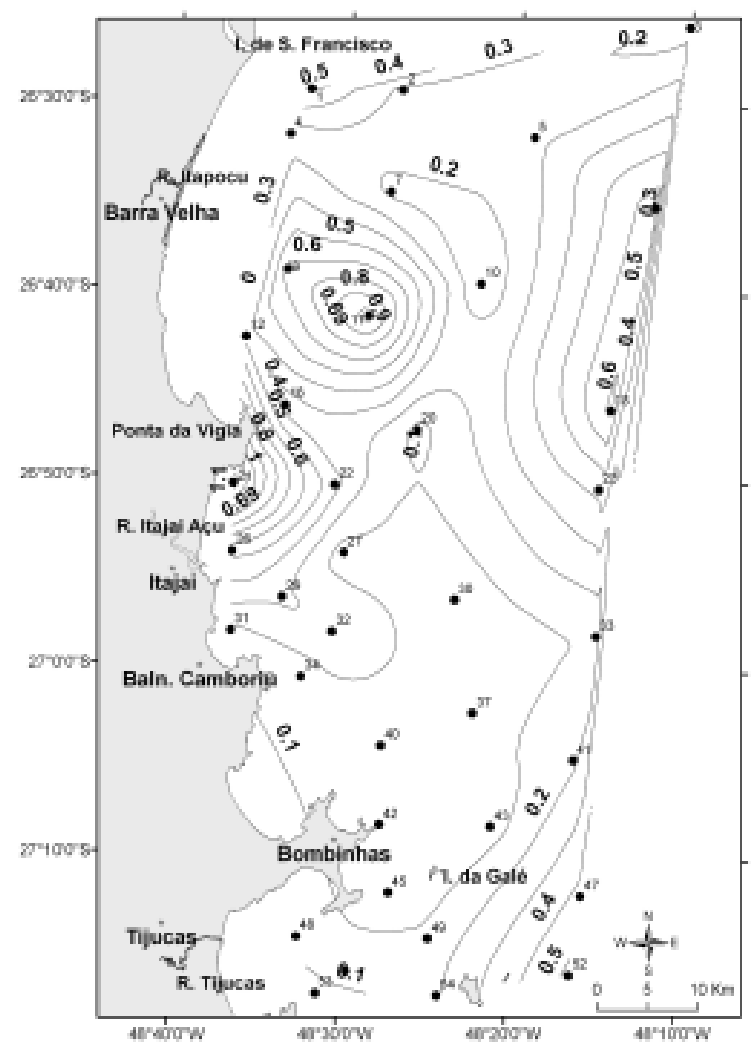

Figura 4: Mapa de concentração de minerais pesados na fração areia fina (2-3 phi).

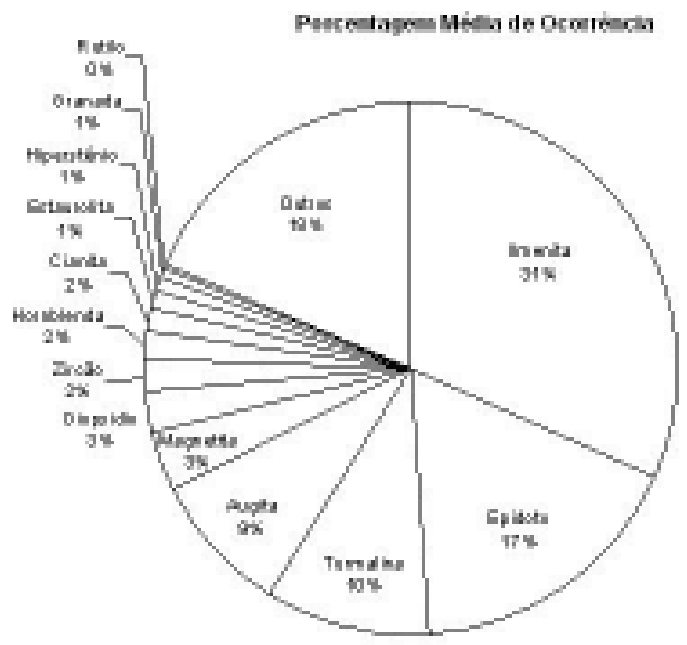

Figura 6: Gráfico contendo as porcentágens média de ocorrência dos principais minerais encontrados.

e estaria concentrando estes minerais. Desta maneira, ficou evidenciado que estes fatores são características decisivas no que diz respeito à distribuição dos minerais e conseqüentemente no padrão de dispersão

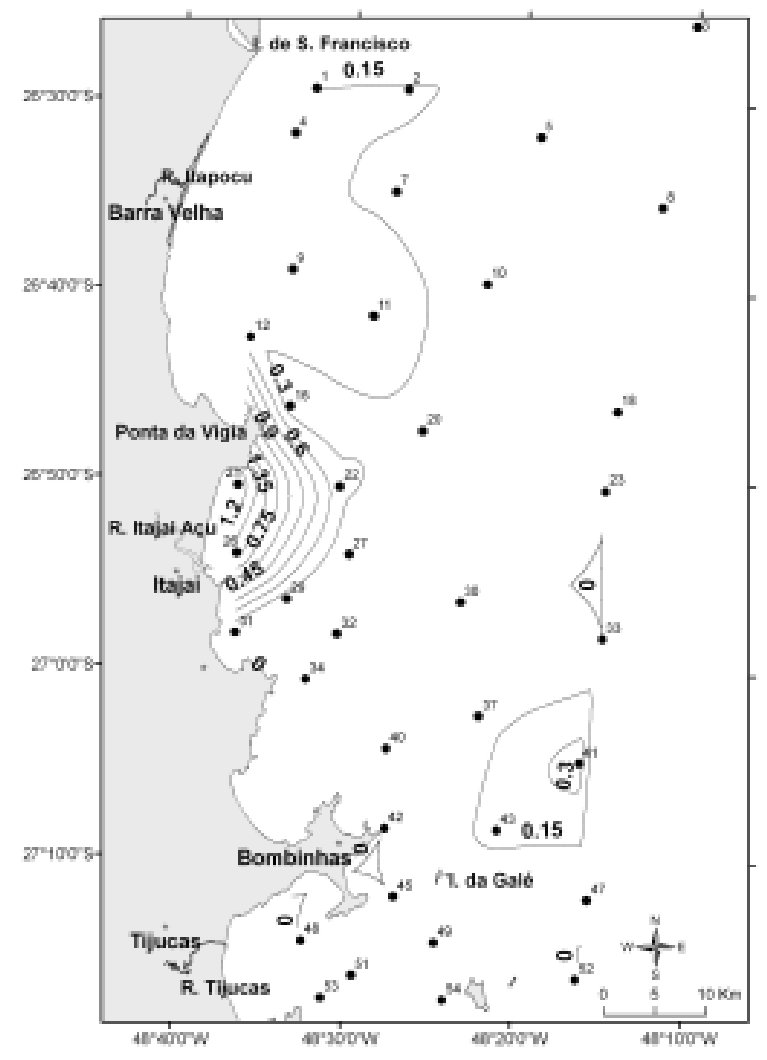

Figura 5: Mapa de concentração de minerais pesados na fração areia média (1-2 phi).

sedimentar. Já os minerais mais maturos estariam associados às áreas de concentração de areais relíquias de plataforma retrabalhadas pela dinâmica costeira.

\section{AGRADECIMENTOS}

Aos Técnicos Laboratoristas do Centro de Estudos Costeiros e Oceânicos, da UFRGS, Gilberto Santos e do Laboratório de Sedimentologia e Geologia, do Centro de Ciências Tecnológicas da Terra e do Mar, Gentil Silvestre. Sem a sua colaboração e ajuda na identificação dos minerais, seria praticamente impossível a conclusão deste trabalho.

\section{REFERÊNCIAS}

Abreu, J.G.N. 1998. Contribuição Sedimentológica da Plataforma Continental Interna de Santa Catarina entre a Foz do rio Tijucas e a Foz do rio Itapocu. Dissertação de Mestrado - Departamento de Geologia, Instituto de Geonuclear, Universidade Federal Fluminense. 
Addad, J.E. 2001. Minerais Pesados: uma ferramenta para prospecção, proveniência, paleogeografia e análise ambiental, São Paulo.

Bates, R.L. \& Jackson, J.A. 1980. Glossary of Geology. American Geological Institute, Falls Church. Virginia, USA.

Calliari, L.J.; Fischler, C.T \& Berquist, C.R. 1990. Heavymineral variability and provenance of the Virginia inner shelf and lower Chesapeake Bay. Virginia Division of Mineral Resources. Virginia, EUA, Publication 103, $124 \mathrm{p}$.

Feo-Codecido, G. 1956. Heavy mineral techniques and their application to Venezuela stratigraphy. Am. Assoc. Petroleum Geologists, Bull. 40: 985-1000.

Krumbein, W.C. \& Pettuohn, F. 1938. Manual of Sedimentary Petrography. Appleton-Century, New York.

Krumbein, W.C. \& Sloss, L.L. 1956. Stratigraphy and Sedimentation. W. H. and Freeman and Co. San Francisco.

Mezzadri, G. \& Saccani, E. 1989. Heavy mineral distribution in late quaternary sediment dispersal in sedimentary basins at active margins. Journal of Sedimentary Petrology. 59 (3): 412-422.

Palma, J.J.C. 1979. Depósitos de Minerais Pesados. Série Projeto REMAC, PETROBRÁS/DNPM/ CPRM/DHN/CNPq. Rio de Janeiro. 10: 33-50.

Pettuohn, F. J. 1957. Sedimentary Rocks. 2 ed. New York, Harper \& Brothers.

Santana, C.I. 1997. Recursos minerais da margem continental brasileira e bacias oceânicas adjacentes. Comissão Interministerial para Recursos do Mar (CIRM) - Grupo de Trabalho sobre Recursos não Vivos da Plataforma Continental, Relat. Inédito, $p$. 20-23.

Suguio, K. 1980. Rochas Sedimentares, São Paulo, Editora Blücher.

Tomazelli, L. J. 1978. Minerais Pesados da Plataforma Continental do Rio Grande do Sul. Acta geológica Leopoldensia, Unisinos, n5 5, vol II, 159 p.

Submetido: Outubro/2004 Revisado: Fevereiro/2005 Aceito: Julho/2005 